and colloid chemistry of the silicate minerals) to explain in fundamental terms the processes occurring in soils. Secondly, it glosses over all debatable points, making no attempt to discuss them, and the inquiring student will find no bibliography. The book, therefore, gives neither a sound training in pedology nor any encouragement to the student to use his powers of reasoning. Instead, it branches off into the reaims of crop husbandry and a very long way from its own title. Further, the book is too long and too expensive for the material it contains, and the reader is irritated by the repetition of section headings in the form of little questions in the text. The inclusion of some good diagrams and photographs and a useful glossary unfortunately do not affect the criticisms given above.

"Introduction to Soil Science" is a far less ambitious book and is considerably shorter and cheaper. It is aimed at a similar audience but with Australian conditions especially in mind. The text is written in a clear, concise style and is readable and interesting. As the author himself points out, the arrangement of the chapters is not as logical as it might be-soil erosion, for example, is considered in the section on soil chemistry rather than with soil physies. Some suggestions for practical work are given in the appendix but, as with the material of the book as a whole, these experiments fall between the requirements of the serious university student and those of the schoolboy who may be interested in soils. There is a short bibliography, mainly applicable to Australian conditions.

"The Study of the Soil in the Field" is a very different proposition. This book, now in its fourth edition, represents the accumulated wisdom of one who has studied soils in the field for many years and who is something of a philosopher. It is primarily a lucid and concise text-book of field procedures and is virtually indispensable for anyone, be he student or practising pedologist, who wishes to study the soil in its natural context. The book is essentially written in the light of experience in Britain, but frequent comparisons are made with conditions elsewhere. A new addition is the chapter on the use of air photographs in soil surveys. It contains useful information on air photographs in general, but becomes rather vague in the section on actual interpretation for soil survey purposes. The photographs with accompanying traces are very interesting, but demonstrate the usefulness of air survey for geological and ecological rather than for pedological purposes.

R. M. S. PERRIN

\section{PRACTICAL INSECT MORPHOLOGY}

Manual of Insect Morphology

By Prof. E. Melville DuPorte. Pp. xi+224. (New York: Reinhold Publishing Corporation; London: Chapman and Hall, Ltd., 1959.) 40s. net.

THIS volume is a publication of the typescript notes used by the author when he was teaching his laboratory class. It gives direct instructions for making nearly two hundred examinations and dissections, using insects that can easily be obtained in quantity. Naturally, North American insects are specified, but equivalent substitutes can be found in other regions. After familiarizing the student with the idea of segmentation, and with the basic con- struction of a segment, the manual gives ten chapters to external structures, and six to internal organs.

Instructions are explicit, and the language is commendably simple and direct. New terms are put in italies the first time that they are introduced, but in spite of this a student would fairly often come upon a word that is not defined in the text nor in the inadequate glossary on p. 6. He would have to remember such words as 'condyle' and 'invagination' from the lectures that he is presumably attending concurrently with his laboratory course.

So far as the text goes, this manual is excellent. It is clearly printed, helpfully divided into convenient sections, and uses a variety of type-faces to the best advantage. It deserves high praise for presenting so much information in such a readily accessible form.

The problem for the reviewer, and for the potential user, is to know what to say about the almost total lack of illustration. There are only fourteen figures, all schematic line-drawings of the simplest kind. We are told that they are intended as a guide to the structure, and that none of them is an exact reproduction of any known insect. In fact, they are the sort of diagram that a lecturer might rough out on the blackboard, talking and explaining all the while; without the lecturer to explain them they do not add much to the text. There are no drawings at all of what one may expect to see after making any of the dissections. "Students are advised to study the drawings in the text-book or other writings of Snodgrass, as well as the work of other competent entomological illustrators." One can sympathize with the author's problem. Two hundred anatomical drawings, fully lettered, would have cost a lot to make, and more to publish. The price of this book is already too high for what it is, and with such figures it would be prohibitive. Yet without any figures I do not see how it can be used by an unaided student. He has neither the time nor the experience needed to be able to apply a verbal description, however lucid, to an unskilled dissection.

The manual may be useful to some experienced entomologists-a demonstrator called upon to give a course in insect morphology, or a specialist in one group who wishes to study the anatomy of related. groups.

H. OldRoyd

\section{ULTRASONIC PROPAGATION}

Absorption and Dispersion of Ultrasonic Waves By Karl F. Herzfeld and Theodore A. Litovitz. (P.ure and Applied Physics : a Series of Monographs and Text-books, Vol. 7.) Pp. xviii +535. (New York : Academic Press, Inc.; London: Academic Press, Ine. (London), Ltd., 1959.) 14.50 dollars.

CINCE the appearance of the paper of P. Debye $S$ on the effects of high-frequency relaxation in the propagation of electro-magnetic waves in substances, much research has been done in that field of study and many books and papers published. Less attention has been devoted to the corresponding relaxation effects in the propagation of compressional waves, though the discovery by G. W. Pierce in 1925 of a dispersion in the velocity of high-frequency sound waves in carbon dioxide gas marked the beginning of new studies which have occupied a considerable number of research workers in physics and physical chemistry since. 